\title{
A SOCIOLINGUISTIC STUDY: A CONTRASTIVE ANALYSIS OF THE ADVERTISEMENTS OF PRIVATE AND PUBLIC INSTITUTIONS IN PAKISTAN
}

\author{
Dr Anser Mahmood, chanser73@yahoo.com \\ Ghulam Hafsa, hafsashah@ymail.com \\ Irum Zahra, Maha Tallat
}

\section{ABSTRACT:}

Department of English University of Lahore Sargodha Campus

\begin{abstract}
It is a qualitative study and aims at providing an in depth analysis of promotional discourse in academic settings, with the focus on the analysis of powerful and hegemonic use of language to publicize, persuade and to hit specific audience, who aspire high to become iconic managers in competitive economic world.
\end{abstract}

Furthermore, the analysis of interdiscursivity as a sign of social change and transitional period. In order to analyze the commercialization of academic discourse of private intuitions of Pakistan, the contrastive analysis, of the advertisements of a private and a public institution, is focused to highlight that the promotional and consumer discourse places consumption in the central position, in the life of people. The comparative analysis of public and private sector not only highlights the marketizing effect on private sector, but also confirms that public institutions in Pakistan still preserve scholarly and academic discourse. They need not to promote and publicize themselves as the previous result and the fame of the institution are the proof of quality edducatin.As it is a sociolinguistic study so, the analysis also reflects the social post modernity transitional period of Pakistani society.

\section{Council for Innovative Research}

Peer Review Research Publishing System

Journal: Journal of Advances in Linguistics

Vol. 5, No. 1

editorjalonline@gmail.com 


\section{INTRODUCTION:}

Global restructuring or the process of globalization after $2^{\text {nd }}$ world war has led towards the world wide social inequalities. The predominant position enjoyed by English as a lingua franca for communication, trade, commerce, international news and technological development has developed a new concept of English as a language of economic opportunity. This process of globalization is leading towards the development of single hegemonic culture. It also has greatlyaffected social discursive practices. In this modern world of competitiveness, marketization the, framing of academic discourse as metaphorical battle isare of wider importance, the traditional concept of academic writings as objectified and author evacuated, is an old story. The use of promotional strategies in academic settings has been on increase since 1990's and has the functional implication of making the product attractive and usable. These are used to emphasis the uniqueness and the value of the product; and also serve as a tool to discursively persuade the recipient for the desired action, which indirectly benefit the producer.

All types of advertisingdiscourses aim at persuading the intended audience, to construct believable stories and to publicize. Thus the language of the advertisements is goal directed, value laden and ideologically loaded. This paper is a text based examination of the markrtization of discursive practices of universities, which is pervasively transforming the world wide academic discourse .Recent changes reflect the impact of the marketization and comodification even in the public sector in West. Institutions of the higher education come increasingly to operate as if they were ordinary business competing to sell their products to consumers. But still a dividing line can be clearly drawn between the discourse of public and private institutions of Pakistan.

The present study is based upon four important aspects: the use of promotional strategies for marketization, the hegemonic use of language for desired interpretation, the discursive positioning of the specific recipient, and lastly discourses as a social matrix.

\subsection{Objectives of the Study:}

1: To analyze the powerful and hegemonic use of the language for the explication of the desired interpretation.

2: To analyze the use of all promotional strategies for their ideological implications.

3: To analyze the discursive construction and positioning of the intended audience.

4: T o analyze interdiscursivity or the articulation of different discourses in a single communicative event, as a sign of social change.

\subsection{Research Questions:}

1: What lexico-grammatical stratégies are used to develop the intended message?

2: What promotional and marketizing strategies are used for personal publicizing?

3: How specific audience is discursively targeted and positioned?

4 : What social aspect does interdiscursivity imply?

\section{LITERATURE REVIEW:}

According to Tao Xiong (2012), the use of rhetorical moves and discourse strategies express the marketization of higher education, contextualized in distinct bureaucracy marked duality in china. The study is based upon the investigation of the corpus of 48 posts in Chinese newspapers. It is an depth analysis of rhetorical moves and strategies and even the structural lay out in the context of marketization. The study analysis the title location, history statement, affiliation programs, statement of programs faculties, incentives and branding as promotional strategies. The subjectification of institution as an agent implies the authorless discourse which is detached from human influence and branding not only provides commercial colouring but also discursively constructs subject positions for potential applicants as being distinguished outstanding and leading figures. Establishing credentials (EC) move is essential constituent in promotional genres which builds a relationship between text producer and receiver, the dominant aspect of the study is the subjectification of institution which gives it an impersonal and authoritative touch, but the mixture of market discourse stresses engagement, affinity and equality with the audience. The study proves that academic jobs advertisements are not objectively informing the audienceof necessary facts, but are more importantly, through promotional strategies, selling themselves.

Ken Hyland (2002), in his study, analysis the visibility and invisibility of authorial self in academic writings and its ideological implications. His study is based upon the corpus of 64 project reports (PR) written by final year Hong Kong undergraduates. Reports are collected from biology, mechanical engineering, information system, business studies, economics and public administrations etc, thus writings from diverse academic fields are analyzed for the visibility and invisibility of writers in their writings and its implication with in relative cultural settings. The point where writers want to assert commitment, use personal pronoun, but where the writers want to disguise responsibility and maintain distance with audience restricts their visibility. In present scenario academic writings not only convey the ideational content, but also the representation of self. The visibility of self or use of first person pronoun implies individual authority and confidence in evaluation and commitment to his ideas. It also reflects implicit desire to gain Credibility. Personal pronoun is a powerful rhetorical strategy for emphasizing a contribution; first person pronoun and possessive determiner assert personal 
contribution and personal involvement or subjectivity. It implies authoritativeness, their commitment to their words. The choice of the first person pronoun gives the writer control over social interaction; it develops writer's relationship with the reader. Thus first person pronoun has multiple implications in the academic writings. The writer on one hand asserts his claim and authority and on the other hand develops social interaction with reader to seek agreement.

According to Nigel Harwood (2005), the use of personal pronoun in academic settings carries the self promotional flavor. This is a corpus based study about constructionist's competitive quest for novelty in academics, which has led researchers towards marketizing and advertizing. And even academic prose of hard scientists, which has traditionally been seen as author evacuated objectified writing. Indisputable and empirical facts use personal pronoun promotional strategy in quest of novelty\& uniqueness. This strategy asserts authority and implicitly express that the reader is novice and in need of direction.

Thus it not only demonstrates categorical commitment to the claim, but also the uniqueness and the novelty of the view which is worthy of attention. The unique feature of the study is that it evaluates the value of personal pronoun in the context of immediate linguistic environment or solid grounds. The promotional context has significant role for the desired implication. The writer refers to two fields: hard and soft or scientific and humanities field. For example in interview settings the use of personal pronoun has no promotional purpose, while its use in abstract opening paragraph alerts the reader for novelty. Thus the study shows that visibility depends upon the function of the purpose, and personal pronoun can't be analyzed without linguistic context. This is the qualitative study based upon the use of personal pronoun in the context of soft and hard disciplines with double implication of asserting the seriousness of personal work and weakness of others.

N.Fairclough (1989) in his book "Language and Power" discusses the basic concepts and structured frame work, for in depth critical discourse analysis. He also emphasizes the analysis of language as a part of social process and change. Language as a social process is to be analyzed in social, intertexual and textual context. The striking feature is that he talks about power in language, and power behind language: that how language is manipulated to get desired impact. The implicit power behind language leads toward the hegemonic use of language for desired interpretation.CDA not only explicates the ideological assumptions behind the language use but also critically analyze the inequality in the society. The second striking feature of this book in that it provides, in sequence, procedures for the explication of the hidden ideological assumptions behind the powerful use of language, through ideologically significant cues and structures. Thus CDA is a structured analysis with the view to highlight the power inequalities in the society. It also analyses language in relation to the social structure, social processes and social change, in order to highlight the dialectical relationship between discourse and society that means both are interlinked and constitute and get constituted by each other.

Marianne Jorgenson \& Louise $J$ Philips (2002) this book provides the basic concepts about the field of discourse analysis and how discourse functions socially and ideologically. This book is comprehensive enough about theory and practice of discourse analysis, it provides comparative analysis of three approaches towards discourse analysis, and also guides that how we can do multiperspectival research combining different analytical discourse analysis approaches and non

discourse analysis approaches. The striking feature of the book is about identity formation and subject positions that how discursively the subject identity and position is structured. Subject is split, fragmented, over determined, and never becomes itself and its identity is represented discursively. The second important feature is relevant to the concerned study that's the concept of interdiscursivity or articulation of different discourses with in an order of discourse and their relationship in a single communicative event. This interdiscursive mixture is the sign of socio cultural change.

All the literature mentioned above has been thoroughly analyzed for being relevant to the objectives of the present study. Tao Xiong and Ken Hyland discuss the promotional strategies in academic settings, while Fairclough provides a systematic model for the structured analysis .The last study by Marianne Jorgenson \& Louise J Philips (2002), specially highlights the point of interdiscursivity. The first study is directly related to the present study as it helps to explicate the implications of the different rhetorical and promotional moves. Statement of programs, use of personal pronoun, statement of incentives and even the structural layout has promotional colouring. This study seems relevant as it focuses on the promotional strategies in academics. Ken Hyland's study also thoroughly discusses the implications of personal pronoun in academic settings. It has several implications in academic writings: it asserts authority, express desire for credibility, and implies personal contribution. Thus this study provides relevant concepts concerning the visibility of the writer as an important promotional strategy. The unique feature of the study is that it evaluates the value of personal pronoun in the context of immediate linguistic environment or solid grounds. The promotional context has significant role for the desired implication, and this unique concept is highly relevant as it helps to explicate the implication of the use of personal pronoun with reference to the linguistic context. Fairclough's book "Language and Power" provides model for the practical and structured analysis. It specially provides the linguistic analysis strategies. Through this model the linguistic cues as verbs, adjectives and sentence structure is systematically analyzed. The book by MarianneJorgenson et al discusses the construction and positioning of the subjects and also interdiscursivity which implies social change thus this book is also directly related to the important objectives of the present study.

\section{METHODOLOGY:}

\subsection{Paradigm:}

Within the constructivist paradigm, the study is an in-depth analysis of the discursive construction of the reality. It is a qualitative study because the purpose of the study is the explication of the hidden ideological intentions behind the hegemonic use of language. A Contrastive analysis is decided as the advertisement of a public institution, presenting utter and diametric contrast, will ease the analysis for not replacing the ideologically significant terms with the neutral terms; 
secondly the objective and neutral style of public institutions will highlight the interestedness in the discourse of the private institutions. The analysis is based upon the combination of framing moves and CDA procedures. Framing is a signaling device for recontexualizing message and will be helpful in analyzing the overall structural implications.

\subsection{Ontological and Epistemological position:}

Within the constructivist paradigm, the ontological position is that reality is constructed, and epistemological position is that construction of the reality is relative and subjective.

\subsection{Population:}

All the private and public universities of Pakistan comprise the population of the study.

\subsubsection{Sample:}

Through the purposive sampling technique, two institutions from Pakistan: "The Institute of Quality and Technology Management the University of Punjab”, and 'Riphah International University' are chosen.

\subsubsection{Research Instruments :}

All the advertisements contain signifiers which send several massages to the reader. Thus the instruments for data generation are: ideologically significant linguistic items as verbs, adjectives, adverbs, pronouns, grammatical structure, positioning, incentives and even over all layout or structure

\section{DATA COLLECTION :}

Through the combination of CDA procedures and framing techniques the primary data is generated from the specified advertisements.

\section{ANALYSIS:}

\subsection{Promotional Strategies used in Advertisement for Marketization \& Desired Interpretation.}

The analysis is framed within the procedures of CDA approach and framing techniques, to analyze the unequal use of language by two types of academic institutions. Ideologically significant linguistic cues as adverbs, verbs, adjectives, sentence structure \& other promotional strategies as motioning of programs, incentives, and physical facilities and overall layout structure are analyzed to highlight the marketization and publicizing in academic discourse. In Discourse analysis of late modernity period, CDA is strongly positioned to address research and theory across the social sciences. As CDA is a critical approach to the language study, it focuses on the relationship between the language and society. Through CDA approach all lexical, structural and promotional procedures are analyzed to bring the implicit message to the foreground, and framing helps to analyze the promotional implications of the overall layout of the advertisement. CDA is the interdisciplinary approach which draws on the fields as pragmatics, Semantics, sociology and even psychology, that's why it suits the concerned study to analyze language in relation to the social change and process. Secondly, it provides the comprehensive linguistic analysis procedures for the explication of the hidden ideological assumptions and functions. And to treat the ads as puzzle to see how the pieces of the puzzle individually and collectively work to persuade, to position the subjects and to publicize etc.

As it is a qualitative and contrastive study, two renowned universities of Pakistan: 'Riphah International University' and "The Institute of Quality and Technology management, The University of Punjab" are selected. The study is based upon the analyses of the difference of language use in the advertisements of private and public educational institutions. And the purpose is in-depth analysis of promotional strategies implied for discursive functional purposes by private institutions. Thus the study highlights the marketization of the private academic sector by contrastive analysis.

The add starts with the over view of 'Management Sciences Discipline' the very lexicalcues as 'Global economic tides"emerging markets"opportunities and challenges' etc. very explicitly expresses the impact of marketization and the competitive environment, the mentioning of scholarships and tuition feewaives: $100 \%$ for $80 \%$ marks or 3.9 CGPA and $75 \%$ tuition fee waive for $75 \%$ mark or 3.75 CGPA'. Such type of the language gives the impact of consumerism in academics. As the mentioning of fee waives and the competitive market scenario is a promotional strategy to make the students aware of the future challenges and indirectly implies as Riphah is the right decision for future guarantee.

Another promotional and marketizing strategy is the mentioning of faculty, with the adjectives as 'Highly Qualified' 'competent"equipped with modern skill \& technology"with student teacher ratio of 1:10' and 'quality enhancement efforts', is also a publicizing strategy to attract the students. The impact of marketization and publicizing explicitly imply the writers aim to present product, and make it attractive and usable in order to show that it is valuable. As the writer is offering some product to be bought.

The use of first person and second person directly imply the conversational discourse and power relation between the writer and the audience.' We offer scholarships' 'Our faculty' 'our qualified staff' etc. This personal and possessive pronoun when analyzed in the hard linguistic context (Nigel Harwood 2005) has multiple implications as a promotional move. The mentioning of first person or possessive pronoun asserts the truth of the proposition and authoritativeness of the writer on the one hand, and on the other hand it implies the self perfection and implicitlyexpresses the weakness of other institutions. This impact is also asserted when the writer in salient features mentions "only Pakistani Universities with 
International presence". Direct mentioning of possessive pronoun and second person also expresses the conversational impact on academic discourse.

The mixing of conversational discourse with academic discourse is also a promotional strategy and asserts the marketization impact. The use of personal pronouns as "we" and "your" express the conversational impact. It implies offering products to be consumed. Marketization and consumer impact requires dealing the audience on equal level. While, this conversational and consumer impact, or interdiscursivity, set against the scholarly style of 'Punjab University' advertisement, highlights the marketizing impact. The Punjab University's advertisement with no promotional strategies, passive construction of sentences and the total missing of personal pronoun imply the pure academic discourse preserved by the public institutions. Unlike the advertisement of Riphah University ,there is no mention of challenging markets, no fee waives or any incentives to implicitly impress upon the audience the only criteria for eligibility is the degree from HEC recognized university and GRE test. The facts are objectively stated without any emotional coloring. Thus the contrastive analysis not only reflect the marketizing impact on private academic discourse but also highlight the dividing line between two educational sectors of Pakistani society. The direct mentioning of programs without any overview or incentives reflects the pure academic discourse preserved by the public institutions.

Riphah International University under the heading of 'salient features' mentions all physical facilities:' Wi-Fi enabled campuses' 'equipped labs' 'libraries' 'hostels'transport'convenient class schedule' etc. the mentioning of incentives is also a promotional move. Other worth noticing moves as recognition by HEC integration of Islamic ethics with modern education and mentioning of address at the end has psychological impact.

The aspect of future guarantee in the competitive market is also a promotional strategy which gives it a consumer colouring. "Graduates are equipped with knowledge \& skill to reach senior positions and become successful managers of future" and the mentioning of "excellent employability for graduates" express future guarantee, and implicitly asserts the excellence of the institution also. The contrastive analysis of ideological significant linguistic cues, adjectives etc. clearly highlight the difference between the languages of advertisements of the public and private institutions. Thus analysis not only expresses contrast of academic and promotional discourse but also implies the relationship between audience and writers. All the technique incorporated by private institutions have the functional purpose of discursively getting the desired interpretation and to publicize and marketizeitself. When all the promotional strategies are removed the scholarly style of public institutions appears. So both the ads present a visible contrast to each other.

The complex declarative sentences of Riphah University imply the expressive modality and categorical commitment to the truth being said, the important thing to be noticed is, the mixing of declarative and passive sentences. Where the qualification of faculty is emphasized complex declarative sentences are used which imply authoritative commitment to the truth being said, while the future incentives are expressed in passive form "successful graduates will be equipped with knowledge and skill" the use of auxiliary "will be" on the one hand imply expressive modality but the absence of agent mitigates the authoritative commitment to the truth being said. The scholarships are mentioned with the first person and declarative sentence. This asserts the truth and commitment.

The double sentence structure has also ideological implications as future guarantee is being implied for promotional purposes but categorically can't be assured. While in contrast the sentence structure,of the advertisement of 'The Institute of Quality and Technology management The University of Punjab', is passive for example :'applications are invited"candidates will be considered"Application forms are to be submitted"application received after due date shall not be entertained' etc. The passive form and hidden agency ideologically imply the objectives and presentation of the facts by maintaining the power distance. The use of 'should be' 'will be' 'shall not be' asserted the categorical commitment to what is being said. Thus the mixture of passive form with expressive modality asserts the commitment and truth more than the declarative sentences. Which shows that without lexical density and promotional strategies, the truth is being asserted more than the advertisement of Riffah International University. This means that truth is self explicit and doesn't require verbosity.

The overall structure of the advertisement also reflects the ideological purpose of marketization. The advertisement of "Riphah International University" shows that $3 / 4^{\text {th }}$ part of the whole advertisement is concerned with promotional strategies,incentives,facilities and publicizing and one part of the whole advertisement is concerned with the hierarchical statement of programs. While advertisement of "The Institute of Quality and Technology management The University of Punjab" also uses statements; but these statements are concerned with the presentation of just required information as eligibility, form submission and test, and even that in detached, objective and scholarly way.

\subsection{Discursive Construction \& Positioning of Subjects:}

The study is based upon the qualitative analysis of the advertisements with the focus on the promotional strategies for marketization and desired interpretation. The analysis of ideologically loaded lexical density and the sentence structure reflects clearly the impact of global maketization on the academic discourse of private institutions of Pakistan.

The second objective of the study is the discursive construction, and positioning of the subjects. When Riphah International University's advertisement is analyzed on the linguistic basis, it targets specific audiences. The cues as 'aspiring' iconic managers' 'entrepreneurs' ' want to reach senior positions' and 'want to become successful managers' reflect the discursive construction of specific audience. The language of Riphah International does not address general audience but only those who aspire high to become iconic managers in competitive economic world. 
Even on the sentence structure level, the relationship can be deduced. The direct declarative sentences with the visible agency, in Riphah International University advertisement, have the expressive value of equal relationship. While, the absence of agency and the use of modal auxiliary verbs as 'should be' 'will not' shall not' and the passive construction of sentences, imply the power relation and distance between the writer and the audience. The words 'should not' will not' should not' imply both expressive and relational modality. On the one hand categorical commitment is asserted and on the other hand authoritative distance is maintained. Thus with the powerful use of language the recipient is not only discursively targeted but also positione.the sentence structure implicitly express that the private institutions deal the students on equal level while the public institutions still maintain their authoritative position.

The advertisement ofThe Institute of Quality and Technology Management the University of Punjab addresses only those audience with degrees from HEC recognized universities as per HEC rules, and have qualified GRE test. No verbosity is implied for the construction of subjects. It implies that how subjects are discursively targeted and positioned. The lexical paucity for the construction of audience also implies the distance with audience. While the conversational way and lexical density not only construct the specific subjects but also reflect the equal relationship between writer and audience.

\section{CONCLUSION:}

The contrastive and qualitative analysis of two institutions reflect the global impact of marketization on private institutions of Pakistan, it also provides an in depth analysis of promotional strategies and their hidden ideological implications for publicizing and for desired interpretations. The in-depth analysis of the advertisements through the specific tools reflect the promotional colouring on the advertisement of Riphah University.All the strategies implied highlight the impact of conversational and consumer discourse on academic discourse.Thus interdiscusivity or the combination of various discourses when analyzed in the context of Pakistani society reflect the transitional Period of the society, as according to Marianne Jorgenson \& Louise J Philips (2002), interdicursivity is the sign of social change. The study shows that the private institutions use the language as a tool to promote themselves. While, the public institutions still maintain the scholarly and objective style, which reflects the impact of post modernity period on the private institutions .But the public institutions are still not affected. It also reflects that the language is used as a powerful tool for the discursive and relative construction of the reality, subject identity and even subject position; as they vary from discourse to discourse. The striking feature of the study is that it not only reflects the global impact of marketization in academic settings but also reflects a dividing line between the language of the advertisements of private and public sectors in Pakistan. Thus clear cut difference reflects the social transitional stage through which Pakistan is passing. In many countries of the world promotional effect is visible in the discourse ofpublic institutions and even scientific writings, but in Pakistan the transitional stage isreflected through contrastive analysis which proves that discourse is a social practice and process which is conditioned by social processes.

\section{BIBLIOGRAPHY:}

1. Bazerman C, N. R. Blyler \& C. S. Thralls 1993. Professional Communication: The Social Perspective. London: SAGE Publications.

2. Edward J. Fox et all 1995. Hour Promotion Work. Published online http://dx.doi.org/10.1287/mksc

3. Fairclough Norman 1989. Language and Power. London: Longman Group.

4. Goodman Shavon, Graddol David 1996. Redesigning English: Next Texts, New Identities. Psychology Press. pp 250.

5. Harwood Nigel 2005. A Corpus Based Study of Self Promotion and We in Academic Writings. Journal of Pragmatics. www.elsevier.com.

6. Hunston, Susan et all 2000. Evaluation in Text. Authorial Stance and the Construction of Discourse. Oxford University Press.

7. Hyland ken 2002. Identity in Academic Writings: Authority and Invisibility Authorial. Journal of Pragmatics. 34. 1091-1112.

8. Hyland Ken 2003. Credibility and Promotion in Academic Publications. Journal of the American Society for Information Science and Technology. Linelibrary.wilay.com.

9. Hyland, Ken, Longman 2004. Disciplinary Discourses. Social Interactions in Academic Writing. Harlow Print.

10. Jorgensen Marianne, Louise J Philips 2002. Discourse Analysis as Theory and Method. SAGE Publications.

11. Joseph E. Zins 2004. Building Academic Success on Social and Emotional Learning. Teachers College Press. Amazon.com.

12. Kubota R,\& Lehner A 2004. Toward Critical Contrastive Rhetoric. Journal of Second Language Writing. 13. 7-27.

13. Lilie Chouliaraki et al 1999. Discourse in Late Modernity Author. Edinburg University Press.

14. Liu Xichon, You Xiaoye 2008. Negotiating into Academic Discourses. International Journal of English Studies. www.um.ejes. 
15. Moravcsik, Michael J, et al 1975. Some Results on the Function and Quality of Citations.

16. Social Studies of Science. 5. 86-92.

17. Paris, S. G et al 1983. Becoming a Strategic Reader. Contemporary Educational Psychology. 8. 293-316.

18. Philips N. \& C. Hardy, 2002. Discourse Analysis. Investigating Processes of Social Construction. SAGE Publications.

19. Swales, J. 1990. Genre Analysis. English in Academic and Research Settings. New York: Cambridge University Press.

20. Wodak Ruth, 2009. Methods of Critical Discourse Analysis. SAGE Publications.

21. Xiong Tao, 2012. Discourse and Marketization of Higher Education in China: The Genre of Advertisements for Academic Posts. Grangdong University of Foreign Studies R.R China.31, 318-337. das.sagepub.com. 